\title{
THE TECHNIQUE OF THE OPERATION FOR ROARING ${ }^{1}$
}

By W. L. Williams, Professor in the New York State Veterinary College, with the collaboration of Assistant Professor J. N. FROST.

The Professors Günther $(6,7,8)$, of the Hanover Veterinary School, were the first to make extended scientific studies of the problem of roaring in horses. They assembled and arranged in such admirable order the literature then existing upon the etiology and clinical characters of the disease that our more recent publications have only served to exemplify and corroborate their views. They placed clearly on record the mechanism of roaring, the impaction of the inspiratory air stream into the laryngeal yentricle, and the resulting inflation of this sac, by which the vocal cords and arytenoid cartilages are forced into the glottis and occlude it. To this nothing material has been added.

From their study of the mechanism of roaring they concluded that any surgical operation for direct cure or relief must be addressed to the vocal apparatus within the larynx, and must either accomplish the elimination of the arytenoid cartilages and vocal cords or bring about their efficient fixation to the laryngeal walls outside the required air passage. In short, they concluded that the cure of roaring demanded the elimination of the impediment to inspiration caused by the dropping inwards and downwards of the vocal cords and arytenoid cartilages. Since their investigations, the efforts of others have been directed wholly to these two objects, except for unimportant efforts at grafting of the recurrent nerve and at cricotomy.

In their publications the Professors Günther $(6,8)$ recorded having investigated the more or less complete excision of the arytenoid cartilages, the vocal cords, and the mucosa of the ventricles. In all they recorded six separate plans of operation. They covered so completely the entire vocal apparatus in their trials that all subsequent operations upon this apparatus necessarily invaded the territory already covered by them.

Amongst the six operation-plans investigated by the Professors Guinther was that of the excision of the mucosa from the laryngeal ventricle. With this, as with each of their other plans of operation, the details of their technique were not given, and no means are now afforded for determining their nature beyond their general aim.

The Günthers failed to bring any of their operation-plans to a successful therapeutic issue. They did not record any clinical operations, but confined their investigations to horses purchased and used for experiment. They did not teach any plan of operation to their students. They did not introduce, recommend, or establish any plan or plans of operation for roaring. In the final publication of K. Güther (8) he recommends, as the most efficient means for the relief of roaring, the operation of tracheotomy already in use prior to the beginning of their investigations.

1 Presented as a Report to the Tenth International Veterinary Congress. 
Before the conclusion of the investigations of $\mathrm{K}$. Günther (8), Cadiot (1), Fleming (5), Hoffman (I 3), Stockfleth, Vennerholm (23), and others had also taken up the investigations, naturally largely influenced by the work of the Professors Günther, and necessarily working over the same field, the vocal apparatus. Their work varied in detail of course, and was more concentrated. While the Professors Gunther investigated six plans of operation, each of the other investigators noted restricted his efforts chiefiy to one of the plans of Giunther, with the hope of modifying the technique in a manner to give more favourable results. Their efforts were in the main confined to the more or less complete excision of the vocal cords or arytenoid cartilages, or both, and no attempt was made, so far as we have found recorded, to cause the adhesion of the vocal cords and arytenoid cartilage to the thyroid cartilage, either by excision of the ventricular mucosa or otherwise. It seems that some of these investigators (23) had made personal visits to Professor Guinther at Hanover, and had enjoyed personal suggestions not found in the Gunther publications. It would appear plausible that $\mathrm{K}$. Günther, conservative, if not pessimistic, regarding all six plans of operation, was the most hopeful regarding the removal of the arytenoid cartilage, and least so toward the excision of the ventricle. This may have accounted for the numerical order in which the six operation-plans were arranged, the most hopeful first, the most hopeless (the excision of the ventricular mucosa) last.

The Cadiot-Fleming-Hoffman-Moeller-Stockfleth-Vennerholm group of investigators were more hopeful at first regarding the operation than Guinther, according to his publications, had become. Some of these, e.g., Moeller and Fleming, actually recommended the operation in no uncertain terms, in very marked contrast to the final statement of K. Günther (8): "Wegen der Unsicherheit des Erfolges habe ich meine Operationsmethode niemals empfehlen und habe sie deshalb auch nicht von den Studierenden ein üben lassen." 1

$K$. Günther, after reviewing the claims of Moeller and others, further states: "Es ergibt sich sonach, dass ein operatives Verfahren auf den bisherigen Wegen nicht zum Ziele führt." ${ }^{2}$ He thus not only disclaims any value of the plans tested by himself, but equally denies that others, e.g, Moeller, have succeeded under the technique advocated by them, and which he declares differed in no important particular from the various techniques investigated by him. $\mathrm{K}$. Giinther finally advises, in his last publication, tracheotomy as the most efficient method for ameliorating the disease.

The group of investigators above cited had accordingly advanced a step beyond the position of the Professors Gunther. The latter had declared all plans of the operation thus far tested to be failures : the Cadiot-Fleming-Hoffman-Moeller-Stockfleth-Vennerholm group had recorded what they thought a higher degree of success, and some of them had actually recommended the technique described. Still they had neither established nor introduced any plan of operation. That is, each failed to convince the profession at large of the practical value of the operation championed, and the actual

1 Because of the uncertainty of the results I have at no time recommended my methods of operation, and have consequently not permitted my students to practise them.

2 It follows, therefore, that operative interference by the plans thus far tried has not led to success. 
performance of the operations was largely restricted to the individua! investigators who had recommended them, ordinarily not more than one or two persons in a nation. The group of optimistic investigators mentioned soon lost ground. Not only did the profession at large reject their recommendations, but each investigator was gradually forced to retreat from the position he had assumed, and either to frankly acknowledge the failure of the operation or quietly to cease to perform or recommend it, so that by 1905 all had virtually, if not formally, come to agree with $\mathrm{K}$. Guinther that thus far no operation for roaring had been made successful.

In America the veterinary profession was only beginning to secure public confidence and support in the last decade of the nineteenth century, and scant opportunity or encouragement had been offered for careful investigations. The profession had not been wholly idle. Butler, Harger, the writer, and others had attempted to follow the work of Fleming, Moeller, and others, but, like them, failed. Merillat (I4) proposed a plan for suturing the vocal cords to adjacent structures, which met with success in exceptional cases, but on the whole failed. The writer investigated another plan for fixing the vocal cords and eliminating the cavity of the ventricle with a loop of gold wire. In some cases he succeeded, but failed in nearly all, and was forced to abandon it.

In 1905 the views of American veterinarians upon this subject were in harmony with those of Günther and other European veterinarians. They had no operation for roaring which they were trying to introduce or cared to recommend or practice. At this juncture the writer decided to investigate the practicability of the excision of the ventricular mucosa, with the hope of inducing adhesion between the vocal cords and arytenoid cartilage and the thyroid cartilage. Our knowledge that the Professors Guinther had previously investigated this plan and announced its failure appeared to us not a positive barrier to further trials. No details of the operative plan of Günther were available, and apparently none are on record. We were accordingly thrown wholly upon our individual responsibility from the start, and had to begin anew upon a plan previously tried and abandoned as a failure, with no knowledge of why it had failed. We must, in order to succeed, change in some material detail a plan which had thus far failed.

Within a year we had so far exceeded our highest expectations that, in 1906, we ventured to present a brief account of our investigations before the American Veterinary Medical Association. It was received with marked scepticism and incredulity. We did not recommend the operation described. A year later we had altered our technique materially, had added cases and increased our successes. Our success had been so marked that it constituted a recommendation for our operation. Merillat had taken courage, and applied our technique with highly satisfactory results. Other American veterinarians then tested the operation, and found it possessed all the merit our communications had suggested, and by I 909 the operation had been frankly accepted and definitely introduced into veterinary practice in America.

Our communications had attracted no attention in Europe. America has far less economic interest in roaring horses than has 
Europe. We have, at least apparently, fewer animals so affected. The investigations in America were being conducted by a comparatively small number of workers. The writer, being in Europe in I909, and believing it would be beneficial to the veterinary profession at large if these investigations could have a wider scope, attempted by personal appeal to interest European leaders. Continental European veterinarians listened with courtesy, and some of them with interest, but no action was taken. In Great Britain the scepticism regarding practical results from the operation was far more marked than on the Continent, with one exception. Hobday promptly took an active interest in the operation, and induced clients to submit two horses to the then chimerical procedure, and they were operated upon in London by Mr Hobday and the writer. Both recovered promptly and satisfactorily. This fact, combined with the published results in America, justified and emboldened Hobday to recommend heartily the operation in his country. It became highly popular with unexampled rapidity, and Hobday's success gained promptly for the operation a foothold on the Continent of Europe. It soon became world-wide. It now stands, according to all available statistics, as the most valuable economically of any corrective operation performed upon animals, although less than eight years have yet elapsed since the first communication by the writer upon the subject, and less than five years since the first two animals handled in Europe by the technique then advised by us were operated upon in London.

The development of the technique has been very rapid, especially following the rapid multiplication of investigators since 1909. The technique described in our communication of 1905 was not at all like that demonstrated to Hobday in 1909, and what Hobday is doing to-day is different in detail from the initial London operations. Eberlein pursues a different technique, and Cadiot yet another, so here, there, and everywhere new details of technique are being developed. The technique of the operation is still in its formative stage, and many important changes are yet to be expected.

One feature only remains intact, the basic idea that firm adhesions between the thyroid cartilage and the arytenoid cartilages and the vocal cords shall be induced by the excision of the ventricular mucosa with a minimum insult to all other structures. Even this central idea has been assailed, though unsuccessfully. O'Connor (I6) in Ireland, and $M$ 'Killip in America, proposed to cauterise the ventricular mucosa, but the plan failed. Like failure awaited Cook, of America, in his effort merely to abrade the mucosa with a finger rasp. With these, and possibly other unimportant exceptions, all investigators since 1909 have remained loyal to the central idea of the operation described by us in our first communication, and each has added more or less materially to the growth of the technique.

It is well to review briefly the development of the technique, and to record concisely the various steps in development, not alone because of the historic interest involved, but because such a record, by describing the obstacles involved and the means taken to overcome them, may aid materially to further the evolution of this highly important operation.

The technique is divisible into three chief parts: the control of 
the patient, the invading incision, or laryngotomy, and the basic operation of the excision of the ventricular mucosa.

The control of the patient, as practised by us at the date of our first communication, was to secure the animal in lateral recumbency upon the operating table, induce complete chloroform anæsthesia, and then place the patient in the dorsal position with the head fully extended. Away from the college hospital the horse was cast, but otherwise similarly handled. Later, with the introduction of the ventricular burr, the general narcosis was displaced by local anæsthesia. Finally, we abandoned the operating table and casting as a rule of practice, and in our clinic at the New. York State Veterinary College have operated for two years exclusively upon the standing animal, securing so far as may be necessary in stocks. Outside our clinic, in cases where stocks are not available, most animals are operated upon standing, sometimes backed into a single stall, often standing free upon the floor, always with local anæsthesia, sometimes with and often without a twitch. A few very resistant animals, in default of stocks, are cast and narcotised.

The question of whether general or local anæsthesia should be used when operating in dorsal recumbency, whether cast or confined upon the operating table, will depend largely upon the behaviour of the patient. Highly resistant animals need be placed under complete general anæsthesia to guard against serious injury to themselves due to violent struggles. Local anæsthesia fulfils all require. ments for the prevention of pain in the operation, but it fails to protect the patient against violent struggling against restraint.

The standing operation has several very distinct advantages. The dangers of casting are eliminated, the patient is spared the fatigue due to casting, and the hæmorrhage is reduced to the minimum, so that it is probably not more than Io per cent. of that accompanying the operation upon the recumbent narcotised animal. There is but scant difference between the recumbent and the standing positions in convenience to the operator and in the time required for the operation.

For local anæsthesia we use 3 gramme cocaine hydrochlor. in about IO cc. of water, with $2 \mathrm{cc}$. of I-IOOO adrenalin chloride solution. Most of this is injected subcutaneously on the median line of the ventral surface of the larynx over the area of intended incision. Later, the remainder is applied to the laryngeal and ventricular mucosa.

The invading operation, the opening of the larynx and the trachea, have undergone many changes. At the beginning of our investigations, as reported in 1906, we made a linear incision on the median raphe of the laryngeal region, beginning opposite to the epiglottis, and carried backwards for a distance of 16 to $20 \mathrm{~cm}$., extending through the skin, and separating the fibres of the sterno-thyrohyoidus muscle down to and exposing the thyroid, cricoid, and first tracheal cartilages. At this point the hæmorrhage was stilled. An incision was then made through the crico-thyroidean ligament throughout its entire length, through the cricoid cartilage, and sometimes through the first tracheal ring. Any hæmorrhage was again stilled, especially an arteriole along the border of the cricoid ring. The incision was then dilated by means of the Mayo appendicitis 
dilator, or other convenient mechanism. Illumination of the larynx was secured by natural light falling from above and behind, downward and forward, or with the aid of a suitable electric lamp.

This plan of invading operation gave us much annoyance and occasionally converted an otherwise successful procedure into a disastrous failure. The cricoid cartilage occasionally became involved in pathological processes, chondritis or perichondritis developed, the cartilage became thickened, deformed, calcified, etc., and occluded more or less the air passage, necessitating tracheotomy.

Hoping to avoid the dangers from severing the cricoid cartilage, we shifted our plan and divided the thyroid cartilage instead, but soon learned that this was no less subject to disastrous disease than the cricoid. Finally, we learned that we could operate with comparative ease through the crico-thyroidean ligament without wounding either the thyroid or the cricoid cartilage. This fact we communicated to Hobday, who in his first publication (9) quotes from our letter, dated 8th December I909, announcing that we had operated thus upon two cases. Hobday at once tested this plan extensively, and enthusiastically introduced it into England and elsewhere. The discontinuance of the wounds of the laryngeal cartilage has proven a distinct advance, increasing the recoveries by probably more than 2 per cent.

Early in our work we attempted upon a few cases to close the invading incision after the completion of the operation, but soon abandoned it. Infection of the wound is virtually inevitable, and the danger from the infection is heightened by closing the wound and excluding light and air. In addition, we may desire to review the operation field during the first few days. The closure of the incision has been rendered yet more untenable by the general adoption of the bilateral operation, which renders post-operative dyspnœa highly probable and necessitates intubation, which is most economically done through the existing crico-thyroidean incision. While we have not had fatalities because of suturing the external wound, others have recorded them.

At the beginning of our investigations we habitually performed tracheotomy, either before or immediately after the chief operation. Merillat (14) early assailed this practice as unnecessary and dangerous, and we soon abandoned tracheotomy except when necessary for the relief of post-operative dyspnœa.

In 1909 we were limiting our interference ordinarily to the left ventricle. Hobday (9-12) soon recommended, and established the value of the bilateral operation. The dangers from post-operative dyspnoea then became greatly intensified, and the need for its control demanded serious attention. Finally we devised a tube, flattened from side to side, which could be readily inserted through the ligamentous incision. We found difficulty, however, in keeping the tube in situ, but finally succeeded by the double means of stout sutures in the cutaneous margins of the wound and tapes tied around the neck of the patient. Thus we have avoided entirely in the invading operation all cartilaginous wounds.

The essential operation has been subjected to very great changes in detail. Up to the time of our first communication we had practised the excision, in addition to the ventricular mucosa, of a 
goodly portion of the vocal cords, along with the atrophic vestiges of the inferior bundle of the thyro-arytenoideus muscle. This proved an error, causing the arytenoid cartilage sometimes to drop too low down and adhere within the cricoid ring, partially obstructing the air passage. This experience reminds us of the statement of K. Güther, "In other cases the cartilage adhered too low down and the animal remained a roarer," and suggests the query whether Günther, too, had not committed this same error, and whether it may not have played an important part in his failure. Gradually we retreated from this practice, and soon came to limit our denudation to the mucosa of the ventricle, including necessarily the mucosa on the lateral or ventricular side of the vocal cords. So far as we have observed, all investigators have, since 1909 , limited the removal of mucosa to this area.

The method of removing the mucosa has varied. The writer at first grasped the mucosa at the angle between the vocal cords and arytenoid cartilage, made an incision through the mucosa with the razor-shaped scalpel, and continued the incision more or less completely around the ventricle. Traction was then applied to the ventricular mucosa with forceps, and the entire sac was carefully dissected out with the scalpel. Hobday, after pursuing the plan advised by the writer for a time, early found that he could more readily detach the mucosa from the ventricle with his index finger after the incision at the margin had been made, and accordingly recommended this plan.

Eberlein adopted a yet different detail in technique, by which he made a very limited triangular incision through the mucosa at the angle formed by the arytenoid cartilage and the vocal cords, forcing the index finger through this down to the bottom of the ventricle outside the mucosa, and then, sharply flexing the finger at the first joint and drawing outwards, everted the mucosa while still attached at most points of the margin of the sac. The plan is yet more simple than that of Hobday.

In America, Blattenberg suggested the use of a steel burr for the removal of the mucosa. This was inserted into the ventricle and revolved upon its long axis until it so engaged the mucosa that it could be everted and drawn out, after which it was excised. The plan appeared so simple that the writer adopted and described it (22). This proved an error. The steel burr tore through the mucosa, abraded the perichondrium of the adjacent cartilage, and caused the very disaster we had so long laboured to avoid. The error taught a lesson, however, which is of value. As in the invading, so in the basic operation, we need have care to avoid wounds or abrasions of the perichondrium and cartilages. Finding the steel burr of Blattenberg unsafe, we tested a soft rubber burr or sphere, which, when wrapped lightly with dry absorbent cotton, grasps the dried ventricular mucosa well, and, so far as we can see, is safe. Sometimes, if there is mucus in the ventricle, the soft rubber burr slips and requires a second or third effort, but this is preferable to the danger of wounding the perichondrium. Cadiot (2), Pfeiffer (17), and others have also devised special steel instruments for detaching the ventricular mucosa. We do not know from the recorded observations how safe they may be. Our own belief at present is that the insertion of sharp, angular, or rough metal instruments into the 
ventricle should be avoided, and suspect that the unprotected finger nail, according to the plans of Hobday and of Eberlein, is not wholly without danger. We believe that here is an important field for further investigation.

According to our present plan, after the invading operation has been completed, the incision through the crico-thyroidean ligament fully dilated and the interior of the larynx wiped free from mucus, the laryngeal and ventricular mucosa is anæsthetised and blanched by the application of the cocaine-adrenalin solution, either with a syringe or with a pledget of cotton or gauze saturated with the liquid and held with forceps. Again drying the ventricle from mucus, we insert the soft rubber burr, covered thinly with dry absorbent cotton, deeply into the ventricle, and revolve it upon its long axis until the resistance indicates that the ventricular mucosa is securely engaged. The revolving of the burr is cautiously continued while traction is exerted upon the handle, and the mucosa slowly and carefully separated from the underlying tissues, everted, and brought out of the ventricle. When the rubber sphere is at the margin of the ventricle, the direction of the tension is changed from a direct line, the handle of the instrument is turned close against the mandible, and the traction now brought to bear upon the side of the rubber burr so that it turns out of the ventricle covered by the mucosa. A pair of curved, serrated forceps with catch is now passed between the burr and the laryngeal walls, closed over the everting ventricular mucosa and secured, and the rubber burr unwound and laid aside. The excision of the ventricular mucosa is then begun near the point of union between the vocal cords and arytenoid cartilage, and while traction is applied to the inverted sac with the forceps, the line of excision is carefully extended around the mouth of the ventricle until the sac is completely excised. The operation is next repeated on the opposite side. The ventricles are wiped free from blood and the denuded tissues in the ventricle touched with tincture of iodine. The retractor is now removed from the laryngeal incision, a stout silk suture is fixed in the skin at the margins of the cutaneous wound on either side, and the laryngeal tube is introduced and secured by the sutures and by a tape passed around the neck.

After twenty-four hours the tube is removed and cleansed, the invading wound is disinfected, and the denuded ventricles are dressed with disinfectants applied with long curved forceps and surgeon's cotton. The dressing is repeated in forty-eight hours, except that, if there is no dyspnœa when the tube is out, it is omitted. If dyspnoea continues, the tube is continued as long as required.

As soon as the tube is omitted, the sutures previously placed in the skin for its retention are removed, and the invading wound disinfected daily, the ventricular wound being left undisturbed. The invading wound heals in about twenty days, when the patient may be allowed walking exercise, to be gradually increased, permitting gentle labour at six weeks and severe work after three or four months.

The principles involved in the operation as at present performed and recommended have for their aim :- 
(I) The control of the patient by the minimum amount of restraint, preferably in the standing position.

(2) Limiting the laryngotomy to an incision through the cricothyroidean ligament without wounding any cartilage.

(3) The removal of the ventricular mucosa from both ventricles, having care not to introduce into the ventricles any sharp, rough, or angular instrument which may abrade or wound the perichondrium or cartilage.

(4) Guarding the patient against post-operative strangling, so far as may be required, by inserting a suitable tube through the incision in the crico-thyroidean ligament.

\section{BIBLIOGRAPHY.}

(I) Cadiot, P. J. : Traitement chırurgical du cornage chronique, I89I.

(2) Cadiot, P. J.: "Traitement chirurgical du cornage chronique. Nouveaux instruments pour l'ablation de la muqueuse du ventricle laryngien," Recueil de Médecine Vétérinaire, 15 mai, I913.

(3) Eberlein, R.: "Tierärztliche Gesellschaft zu Berlin," B.T.W., I9I 2, p. 520 .

(4) Eberlein, R.: "Die operative Behandlung des Kehlkopfpfeiffen der Pferde. Excision der seitliche Kehlkopftasche," Archiv Tierheilk., Bd. XXXVIII., s. 409 .

(5) Fleming, George : Roaring in Horses, I889.

(6) Günther, K. : Topographische Myologie des Pferdes, 1866.

(7) Günther, K. : Studien über Kehlkopfpfeiffen der Pferde, 1893.

(8) Günther, K.: Studien ïber das Kehlkopfpfeiffen der Pferde, 2 Auflage, 1896 .

(9) Hobday, Frederick: "A Preliminary Note upon the New Operation for Roaring in Horses," Veterinary Journal, January r910, Vol. LXVI., p. 23.

(Iо) Hobday, Frederick: "The Newly-Introduced Roaring Operation," Veterinary Record, I6th April I9I0, Vol. XXII., p. 692.

(I I) Hobday, Frederick: "The Newly-Introduced Roaring Operation : An Improvement and a Warning," Veterinary Journal, August 1910, Vol. I.XVI., p. 487 .

(I 2) Hobday, Frederick: "Some Further Remarks on the Roaring Operation," Veterinary Record, 29th October r9ro, Vol. XXIII., p. 276.

(x 3) Hoffman, Professor L : Tierärztliche Chirurgie, Band I., I 892.

(14) Merillat; L. A. : Discussion in Proceedings of American Veterinary Medical Association, 1907, p. 430.

(15) Moeller, H.: Das Kehikopfpeiffen der Pferde und Seine Operative Behandlung. 1888 .

(16) O'Connor, J. J.: "Roaring, New Method of Operating for," Veterinary Record, i 7 th September i9 10, Vol. XXIII., p. I68.

(17) Pfeiffer, W.: "Zur Technik der Exstirpation der Stimmtasche bei

Kehlkopfpfeiffen," B.T.W., 2 mai, I9I2, Vol. XXVIII., p. 3 I 3.

(I8) Pfeiffer-Williams: Surgical Operations, I 900.

(19) Williams, W. L. : "Notes on the Surgical Relief of Roaring," Proc. A.V.M.A., I906, p. I 79 .

(20) Williams, W. L. : "The Surgical Relief of Roaring," Proc. A.V.M.A., I 907, p. 430 .

(2 I) Williams, W. L. : Surgical and Obstetrical Operations, 1907.

(22) Williams, W. L. : Surgical and Obstetrical Operations, I9I 2.

(23) Vennerholm, Professor Dr John: Specielle Operationslehre des

Pferdes, 1907 , p. 175 . 